\title{
Real and Perceived Physical Functioning in Italian Elderly Population: Associations with BADL and IADL
}

\author{
Filippo Candela1, Giulia Zucchetti1, Daniele Magistro ${ }^{1,2 *}$, Enrique Ortega ${ }^{3}$, \\ Emanuela Rabaglietti ${ }^{1}$ \\ ${ }^{1}$ Department of Psychology, University of Torino, Torino, Italy \\ ${ }^{2}$ Department of Functional Brain Imaging, Tohoku University, Sendai, Japan \\ ${ }^{3}$ Health Science Department, California State University, Dominguez Hills, Carson, USA \\ Email: ${ }^{\text {danielemagistro@gmail.com }}$
}

Received 12 August 2014; revised 18 September 2014; accepted 17 October 2014

Academic Editor: Jolanta Dorszewska, Poznan University of Medical Sciences, Poland

Copyright (C) 2014 by authors and Scientific Research Publishing Inc.

This work is licensed under the Creative Commons Attribution International License (CC BY). http://creativecommons.org/licenses/by/4.0/

\section{(c) (i) Open Access}

\section{Abstract}

This study aimed to identify the key physical abilities (aerobic endurance, gait speed, balance, strength) and psychological variables associated with the level of basic (BADL) and instrumental (IADL) activities of daily living in an autonomous community-dwelling elderly population in Italy. 135 elderly people $(63 \%$ women; mean age $=73.3, S D=5.5)$ were included in the study. Stepwise regression was performed to verify the association between these variables and the level of BADL and IADL in the elderly participants. Results showed that balance $(\beta=-0.21, p<0.01)$ and perception of physical functioning $(\beta=0.32, p<0.0001)$ were the key individual variables related to BADL scores, and IADL score was associated with perception of physical functioning $(\beta=0.30, p<0.0001)$ and upper limb strength $(\beta=0.21, p<0.05)$. The results demonstrate a relationship between physical functioning and ADL, both real physical functioning and perceived physical functioning.

\section{Keywords}

Physical Functioning, ADL, Psychological Status, Elderly

\section{Introduction}

Autonomy in performing Activities of Daily Living (ADL) is crucial for successful ageing in our society [1]. The ${ }^{*}$ Corresponding author.

How to cite this paper: Candela, F., Zucchetti, G., Magistro, D., Ortega, E. and Rabaglietti, E. (2014) Real and Perceived Physical Functioning in Italian Elderly Population: Associations with BADL and IADL. Advances in Aging Research, 3, $349-359$. http://dx.doi.org/10.4236/aar.2014.35045 
loss of autonomy in performing Basic ADL (BADL: eating, dressing, walking, bathing, using the toilet, personal hygiene) and Instrumental ADL (IADL: preparing lunch and dinner, doing light and heavy household activities, shopping, managing personal finances) has a significant impact on the well-being of an individual, and often leads to institutionalization [2] [3] and an increased risk of mortality [4] [5] (Hjaltadottir et al., 2011; MillanCalenti et al., 2010).

According to Vermeulen and colleagues [6] who undertook a review of the literature on this topic, a variety of different physical abilities have been suggested as predictors of BADL and IADL. Excluding elderly with severe physical or cognitive impairments such as stroke or dementia, physical abilities seem to play a relevant role in the maintenance or loss of BADL and IADL. The daily activities of an individual, such as moving, dressing, bathing, cleaning the house and shopping, all require certain physical abilities to execute. Vermeulen and colleagues [6] reported the following predictors in their review: gait speed (12 studies), muscle strength (10 studies), balance (6 studies) and lower limbs (5 studies). A review by Stuck et al. [7] emphasised the predictive role of the lower and upper limbs. The role of lower and upper limb strength, gait speed and balance in the maintenance of ADL has also been confirmed by many other studies [8]-[11]. Based on the large amount of research on this topic, we can conclude that physical abilities probably represent the most important individual factors related to BADL and IADL in the elderly.

As a result of the reported direct link between physical functioning and ADL, many studies have attempted to design physical interventions to improve not only the physical abilities of the elderly but also their ADL. However, these studies have shown contrasting results. Chou and colleagues [12] conducted a meta-analysis of the effects of eight trials on the physical abilities and ADL in an elderly population. The results demonstrated a significant positive effect of these interventions on the physical abilities and ADL performance of the elderly participants, who exhibited significantly superior performance in ADL compared with the control group. Conversely, the meta-analysis by Gu and Conn [13] took into account 19 studies and emphasised that these trials, despite a significant positive effect on physical abilities, did not improve ADL in the elderly. Thus, both metaanalyses confirmed the positive effects of physical activity programs on the physical functioning of the elderly, but only the research of Chou and colleagues [12] found a significant effect of these programs on ADL. Daniels and colleagues [14] in their review confirmed the positive effects of physical training on physical abilities but not on ADL. They argued that physical activity programs were not effective in the improvement of ADL because they only affected physical functioning, ignoring psychological, social and environmental factors. Thus, there are no clear conclusions regarding the effectiveness of physical activity programs on the promotion of ADL in the elderly.

When analysing the literature on this topic, two main shortfalls can be identified. First, the studies on ADL and physical abilities do not take into account the wide range of physical abilities of the elderly, and this may have resulted in the omission of some of the most relevant physical aspects related to ADL. Therefore, the main physical abilities related to ADL in the elderly remain unclear. According to Gu and Conn [13], it is necessary to identify the physical performance measures that most strongly correlate with ADL. Second, the interventions for physical abilities and ADL have not considered the possible role of the elderly's perception of their physical abilities. Although physical abilities are the main factors linked to ADL in the elderly, certain constructs belong to the psychological realm of the physical condition, e.g. self-rated health, pain perception and perception of physical functioning. Each of these aspects has a relevant role in the well-being and functionality of the elderly and has a significant connection with physical abilities. For instance, self-rated health is considered a main concept related to the well-being of an individual and a strong connection with mortality risk has been demonstrated [15] [16]; in fact, studies have demonstrated the connection between perceived health and functional limitations [17] [18]. Similarly, pain perception is related to well-being in the elderly [19], and it has a significant impact on their level of disability [20]. Finally, regarding the perception of physical functioning, our previous study [21] (Candela et al., 2013) highlighted that BADL is strongly associated with the perception of physical functioning among institutionalised elderly people. Many studies have confirmed that an individual's perceived dimension of their own body and their own health can play a significant role in the level of disability and functionality in the elderly. Therefore, these psychological aspects could also be significantly related to ADL in the elderly. Furthermore, the role of depression should be also taken into account. Depression reportedly has an indirect role in physical performance. In fact, elderly people with signs of depression may limit their daily physical activities, resulting in the worsening of their physical functioning [22] [23]. Furthermore, Schneider and colleagues [24] reported that elderly people with a high level of depression had low subjective health perception. Thus, traits of depression can indirectly influence ADL, modifying both the real physical functioning and perceived variables 
related to health.

In summary, the relationship between ADL and physical abilities is particularly complex and requires more clarity. So far, the research has not shown definitive findings with regard to the main physical abilities related to ADL, nor has it taken into account the effect of psychological factors on the body and its functioning. Two main questions need to be discussed. The first is the identification of the most important physical abilities associated with BADL and IADL in the elderly. The second is the analysis of the possible impact of self-rated health, pain perception and perception of physical functioning on ADL in the elderly. We argue that better interventions can be designed through more specific understanding of the physical and psychological variables related to BADL and IADL. Furthermore, this knowledge could facilitate the analysis and management of the barriers to autonomy in the elderly in their daily life: clinical evaluations, preventative activities and rehabilitation strategies could be more effective by addressing the main variables significantly correlated with ADL. The identification of strategies to promote and maintain ADL in the elderly is in urgent need, considering the negative effects that the loss of ADL has on the well-being of patients and also on the health care costs for institutions [25]. Therefore, it is vital that we obtain complete and definitive results about the relationship between ADL and physical abilities, also taking into account the psychological variables linked to the body and its functioning, as well as the effects of depression.

For these reasons, we investigated the association between BADL and IADL and a large set of physical abilities and psychological constructs with an aim to clarify the relationship between ADL and physical functioning.

\section{Aims}

We aimed to identify the main physical and psychological correlates of BADL and IADL in a large group of Italian elderly people. We investigated the association between BADL and IADL and many physical abilities and perception variables about the body and its functioning. Specifically, with respect to physical abilities, we considered together aerobic endurance, gait speed, balance, strength of upper and lower limbs and lower back and hamstring flexibility in order to elucidate only the physical abilities that are significantly linked to BADL and IADL in the elderly. These variables represent the most common physical abilities related to ADL in elderly [6] and are most commonly analysed in the evaluation of functional fitness in the elderly [26].

The psychological variables considered were self-rated health, pain perception and the perception of physical functioning. These constructs, which belong to the area of perception, are strictly linked to the real physical condition and to the risk of disability in the elderly. According to Covinsky et al. [20], Schinittker [17] and Johnson and Wolinsky [18], elderly people with high pain perception or low self-rated health have more risk of developing worsening disability over time. Moreover, we considered the possible moderating effect of depression. Pre-existing depression is a risk factor for the onset of disability, acting mainly on physical and health functioning [22] [23]. Finally, in our study, we distinguished between BADL [27] (Katz et al., 1963) and IADL [28] (Lawton \& Brody, 1969) because this distinction is more effective in the analysis of autonomy and disability in the elderly [29].

Based on the literature already cited [17] [18] [20], we hypothesised that both BADL and IADL were related not only to physical abilities but also to perceived variables. Among the aforementioned physical abilities, we hypothesised that balance is the main ability linked to ADL. According to Sturnieks and colleagues [30], balance is a fundamental skill for daily life because it is related to the risk of physical disabilities and falls [31]. With respect to the psychological variables, we hypothesised a strong relationship between the perception of physical functioning and BADL and IADL. Unlike pain perception and self-rated health, the perception of physical functioning represents more effectively how the elderly perceive their body and its functioning.

\section{Method}

This cross-sectional study is part of the "Act on Ageing" project, a major project conducted by the Department of Psychology of the University of Turin. In this project, the elderly in the Piedmont Region were recruited if they met the following two criteria: 1) age $\geq 65$ years and 2) no severe cognitive and physical impairments. All the elderly recruited were living autonomously at their own homes in the Piedmont Region of Italy.

\subsection{Participants}

Our study was approved by the Ethical Committee of the University of Torino, and the participants were in- 
formed that participation in the study was voluntary and confidential. Elderly participants were recruited in from senior centres in the Piedmont Region. From a list of 400 elderly, we randomly contacted 250, informing them of our research project. All participants provided written informed consent, in accordance with Italian law and the ethical code of the Italian Association of Psychologists. The Mini Mental State Examination Test [32] was used to evaluate cognitive function and all participants reached or exceeded the minimum score of 24. For the "Act on Ageing" project, a part of the original sample was involved in a complex and specific physical assessment with a large battery of physical tests. This specific sample was created randomly and comprised 135 people, 85 females (63\%) and 50 males (37\%). The gender differences of our sample are due to the social situation of elderly in Italy where women live on average five years longer than men [33]. The mean age was 73.3 years ( $\mathrm{SD}=5.5)$. The majority were married $(54 \%, \mathrm{~N}=72)$ or widows/widowers $(34 \%, \mathrm{~N}=46)$, whilst others had never married $(4 \%, \mathrm{~N}=6)$ or were divorced $(8 \%, \mathrm{~N}=11)$. In terms of education, participants were divided into two levels: "low", corresponding to compulsory education (only primary school, $47 \%, \mathrm{~N}=62$ ) and "high", corresponding to additional non-compulsory education (more than primary school, $53 \%, \mathrm{~N}=73$ ). In terms of former occupation, participants were divided into manual $(51 \%, \mathrm{~N}=69)$ and non-manual labour $(49 \%, \mathrm{~N}=66)$.

\subsection{Measures}

We administered a psychological questionnaire to the elderly recruited. In addition to this, motor science researchers administered a battery of physical tests. We also verified the level of BADL and IADL. All the participants were assessed individually.

We administered the Groningen Activity Restriction Scale-GARS [34] to assess the level of BADL and IADL. This scale is composed of 18 items that represent 18 ADL (11 items for BADL, score range 0 - 44; 7 items for IADL, score range 0 - 28). Participants were asked to indicate whether they are able to execute 18 daily activities autonomously and whether they have difficulty or dependence on others to complete the activity. As indicated by Gill and collaborators [35], responses to questions about difficulty and dependence provide complementary information that contributes to the overall picture of the continuum of disability. The Cronbach's alpha was 0.89 for the BADL scale and 0.87 for the IADL scale.

The 6-min walking test [36], in which the participants walk around a course for 6 min, assessed aerobic endurance. The number of metres walked represented the measure of aerobic endurance. By dividing the number of metres walked in 6 min, we obtained a measure of gait speed. The 30-s chair-rise test [36], in which participants have to execute the highest possible number of stands in $30 \mathrm{~s}$, assessed the lower body strength. The number of full stands completed in $30 \mathrm{~s}$ represented the measure of lower limb strength. The arm curl test [36], during which participants had to execute the largest possible number of bicep curls in $30 \mathrm{~s}$ using a hand weight of 5 lbs for women and $8 \mathrm{lbs}$ for men, assessed upper body strength. The number of curls completed in $30 \mathrm{~s}$ represented the measure of upper limb strength. The timed "Up and Go" test [37], whereby the subject had to stand up from a standard chair, walk $3 \mathrm{~m}$, walk back to the chair and sit down again, assessed static and dynamic balance. The number of seconds needed to complete the test represented the measure of static and dynamic balance. The sit and reach test [38] assessed the flexibility of the lower back and hamstring muscle. Participants were asked to sit on the floor with legs fully extended and the heel of their bare feet against a box. Participants then placed one hand on top of the other, slowly bent forward and reached as far as possible along the top of a ruler, holding the stretch for $2 \mathrm{~s}$. The distance reached represented the measure of the flexibility of the lower back and hamstring muscle.

We administered the Italian version of the 36-Item Short Form Health Survey Questionnaire (SF-36) [39]. Specifically, we considered the questions about general self-perception of one's health status. The possible answers ranged from 1 (bad) to 5 (excellent). We also considered the question about pain perception in the last four weeks. The possible answers ranged from 0 (very severe) to 5 (no pain). Moreover, we administered questions in the physical functioning dimension, which comprised 10 questions about the perception of body limitations during different kinds of activities (for example, "does your health limit you in vigorous activities/moderate activities/lifting or carrying groceries/climbing several flights of stairs/bending, kneeling or stooping/walking/bathing or dressing?") The range of possible answers was 3 "yes, limited a lot” to 1 "no, not limited at all”. The higher the total score, the higher the perception of limitations of physical functioning. The Cronbach's alpha of the physical functioning scale was 0.88 .

Finally, the Centre for Epidemiologic Studies Depression Scale (CES-D) in the Italian version [40] was used 
to assess depressive traits: the scale is composed of 20 items that correspond to 20 depressive moods. Participants must indicate how often they have felt specific feelings in the last week $(0=$ rarely; $1=$ some or a little of the time; 2 = occasionally or a moderate amount of the time; 3 = most or all of the time; range $0-60$ ). We considered a score of $\geq 16$ to indicate the presence of depressive symptoms. The Cronbach's alpha of the CES-D scale was 0.88 . Mean, standard deviation, median, minimum, maximum, skewness and kurtosis of each variable are summarised in Table 1.

\subsection{Data Analysis}

First, participants were categorised as either non-depressed (depression score $\leq 16$ ) or depressed (depression score $>16$ ). As the main aim of this study was to determine from a broad range of physical and psychological variables those that are significantly associated with BADL and IADL scores, we conducted a stepwise regression analysis with backward elimination. A stepwise regression analysis represents a particular type of regression where the choice of predictive variables is carried out by an automatic procedure and it can be used to develop the best model starting from the independent variables [41]. Specifically, the backward elimination method begins by placing all of the predictors under consideration in the model. The system deletes one at a time until it reaches a point where the remaining variables all make significant partial contributions to predicting the dependent variable. In this study, two stepwise regression analyses were conducted, with BADL and IADL, respectively, as dependent variables. The following scores were included in each model: perception of physical functioning score, self-rated health score and pain perception score as well as the scores of 6-min walking test and gait speed, chair and rise test, arm curl test, Timed Up and Go test and sit and reach test. The depression categories were entered into the model as moderators. As moderators, the categories interact with the independent variable to predict outcome scores; that is, certain levels of moderator under certain conditions of the independent variables may predict different levels of the dependent variables. According to Baron and Kenny [42], the moderation effect verifies the direct effect of each independent variable on the dependent variable (Path A), controls for the impact of the moderator (Path B) and evaluates the effect of the interaction or product of the two (Path C). For each regression, we controlled for age and gender. The significance level was set at $\mathrm{p} \leq 0.05$. The Statistical Package for Social Sciences (SPSS 20.0 for Windows) was used for all statistical analyses.

\section{Results}

In the analysis of Model 1 with BADL as the dependent variable, the backward-elimination approach required 16 steps to obtain the final model ( $\mathrm{F}=16,182$; d.f.2, 133 ; $\mathrm{p}<0.0001, \eta^{2}=0.19$ ). The system progressively excluded self-rated health (step 1), the moderation between depression and the arm curl test score (step 2), the arm

Table 1. Descriptive analysis of all study variables.

\begin{tabular}{cccccccc}
\hline & Mean & SD & Median & Minimum & Maximum & Skewness & Kurtosis \\
\hline BADL & 41.4 & 5.2 & 42 & 0 & 44 & 0.9 & 0.8 \\
IADL & 24.7 & 4.9 & 27 & 1 & 28 & 0.7 & 0.6 \\
Physical functioning & 21.4 & 4.3 & 22 & 9 & 27 & -0.8 & 0.3 \\
Pain perception & 3.1 & 1.4 & 3 & 0 & 5 & -0.1 & -0.9 \\
Self-rated health & 1.4 & 0.8 & 1 & 0 & 4 & -0.1 & -0.8 \\
Sit and reach test & -5.1 & 9.9 & -5 & -32 & 23 & -0.03 & 0.2 \\
Six minutes walking test & 414 & 82.5 & 403 & 200 & 683 & 0.3 & 0.2 \\
30 seconds chair-rise test & 10.1 & 2.8 & 10 & 2 & 18 & 0.1 & 0.4 \\
Time up and go test & 8.6 & 6.1 & 8.3 & 5 & 20.3 & 0.8 & 0.7 \\
Arm curl test & 18.9 & 6.1 & 19 & 2 & 34 & -0.1 & -0.2 \\
Gait speed & 69.1 & 13.7 & 67.2 & 33.3 & 113.8 & 0.3 & 0.17 \\
Depression & 17.8 & 10.7 & 17 & 0 & 50 & 0.6 & 0.05 \\
\hline
\end{tabular}


curl test score (step 3), the chair rise score (step 4), the gait speed and 6-min walking test scores (step 5), the sit and reach score (step 6), the moderation between self-rated health and depression (step 7), the moderation between chair rise score and depression (step 8), the moderation between depression and pain perception (step 9), the moderation between depression and Timed Up and Go score (step 10), the moderation between depression and gait speed (step 11), the moderation between depression and sit and reach (step 12), the moderation between depression and the 6-min walking test score (step 13), pain perception (step 14), the depression categories (step 15) and the moderation between depression and physical functioning (step 16). The final model revealed a significant relationship between BADL score and physical functioning scores $(\beta=0.47, \mathrm{p}<0.0001)$ and Timed Up and Go scores $(\beta=-0.32, \mathrm{p}<0.05)$. The final model is shown in Table 2.

In the analysis of Model 2 with IADL as the dependent variable, the backward-elimination approach required 15 steps to obtain the final model $\left(\mathrm{F}=13,008\right.$; d.f.2, 133 ; $\mathrm{p}<0.0001, \eta^{2}=0.23$ ). The system progressively eliminated the moderation between depression and gait speed score and 6-min walking test score (step 2), the gait speed and 6-min walking test score (step 3), the moderation between depression and Timed Up and Go score (step 4), the depression categories (step 5), the sit and reach score (step 6), the pain perception (step 7), the moderation between depression and pain perception (step 8), the moderation between depression and physical functioning (step 9), the moderation between depression and arm curl score (step 10), the moderation between depression and chair rise test (step 11), the moderation between depression and self-rated health (step 12), the chair rise test score (step 13), the self-rated health score (step 14) and the moderation between depression and sit and reach score (step 15). The final model revealed a significant relationship between IADL score and physical functioning score $(\beta=0.26, \mathrm{p}<0.01)$ and arm curl score $(\beta=0.29, \mathrm{p}<0.05)$. No other variable contributed significantly to the model and no moderation effect of depression was found. Model 2 is summarised in Table 3 .

The analysis revealed two models based on the regression formula $\mathrm{y}=\mathrm{a}+\mathrm{b} 1 \times 1+\mathrm{b} 2 \times 2+\mathrm{e}$. Each model consisted of two dependent variables (BADL and IADL scores) regressed respectively on the physical functioning and Timed Up and Go score (BADL) and on the physical functioning and arm curl score (IADL). The two models explained about the $20 \%$ of the variance (19\% for the BADL model and $23 \%$ for the IADL model), indicating the goodness and the statistical power of the analysis.

\section{Discussion}

This study aimed to identify the main physical abilities and psychological variables associated with BADL and IADL in a group of autonomous elderly Italian people. Despite the recognised existence of a strong connection between ADL and physical abilities in the elderly [6], some important questions on this topic remain. First, although there a large number of studies about ADL and physical abilities, there is still not clarity around the main variables linked to ADL. In fact, few studies have taken into account a comprehensive range of key physical abilities in order to isolate those strictly linked to ADL. We assume that this could be due to the difficulty in the administration of a complete battery of physical tests that account for all key physical abilities.

Table 2. Final model with significant predictors of BADL using stepwise regression with backward elimination.

\begin{tabular}{ccccc}
\hline N $=135$ & \multicolumn{4}{c}{ BADL } \\
\hline Predictors & $\boldsymbol{B}$ & $\boldsymbol{S E}$ & $\boldsymbol{\beta}$ & Sig. \\
\hline Perception of physical functioning & 0.55 & 0.13 & 0.47 & 0.0001 \\
Time Up \& Go test score & -0.48 & 0.24 & -0.24 & 0.028 \\
\hline
\end{tabular}

Table 3. Final model with significant predictors of IADL using stepwise regression with backward elimination.

\begin{tabular}{ccccc}
\hline N $=135$ & \multicolumn{4}{c}{ BADL } \\
\hline Predictors & $\boldsymbol{B}$ & $\boldsymbol{S E}$ & $\boldsymbol{\beta}$ & Sig. \\
\hline Perception of physical functioning & 0.29 & 0.11 & 0.26 & 0.006 \\
Arm curl test score & 0.24 & 0.12 & 0.29 & 0.045 \\
\hline
\end{tabular}


Secondly, few studies took into account psychological variables specifically related to the body and its functioning. Researchers who deepened our understanding of the relationship between ADL and physical abilities did not consider the importance of the perceived dimension of the body and its functioning. We hypothesised that these psychological variables could have also a significant relationship with ADL; that is, elderly people with poor perception of their own health and of their physical functioning will be at major risk of loss of ADL.

We believe that the lack of clarity on the topic can explain the discordant results on the effects of physical activity programs on promotion of ADL in the elderly. In fact, there is currently no agreement about whether specific physical activity programs can improve ADL in the elderly [12] [13]. In our study, we attempted to clarify these questions, considering the following key physical abilities; aerobic endurance, gait speed, balance, strength of lower and upper limbs, flexibility of lower back and hamstring muscle, as well as various psychological variables (self-rated health, pain perception and perception of physical functioning) to identify the variables significantly linked to BADL and IADL.

With regard to BADL, results indicated a significant association with balance skill and the perception of physical functioning. These findings are consistent with many other studies [8] [43] that evidenced balance skill as one of the main predictors of ADL performance. Perception of physical functioning, together with strength of upper limbs, were the main variables associated with IADL. These findings give rise to many different considerations.

First, our study excluded many physical abilities that other studies [6] have demonstrated to be related to BADL and IADL in the elderly. Although these variables may also be associated with BADL and IADL, our study suggests that balance and upper limb strength have a stronger relationship with BADL and IADL in the elderly. The key role of balance has been confirmed by research. For instance, Okumya and colleagues [44] confirmed that balance skill, specifically measured by the Timed Up and Go test, was able to detect functional decline in BADL. Moreover, balance skill is associated with the risk of fall in the elderly [45] that is, in turn, related to the loss of ADL both in elderly living autonomously and in institutions [46]. In general, balance is a fundamental pre-requisite for daily mobility [30]. Considering IADL, the significant relationship with upper limb strength seems to be related to specific activities investigated by our questionnaire related to activities such as doing heavy cleaning, washing clothes, making the bed and shopping. These activities primarily require upper limb strength.

It appears that the physical predictors of IADL depend essentially on the daily activities investigated in any given study, because different patterns of activity require different physical abilities. In the present study, IADL were different from those investigated by other instruments such as the IADL Lawton Scale [28] that includes other activities like using the telephone, being responsible for personal medications, handling finances, etc. Thus, researchers should be careful about generalising their predictors of IADL findings because different instrumental activities correspond to different physical abilities.

Considering the psychological variables, both BADL and IADL were significantly related to the perception of physical functioning, indicating a clear association between the level of autonomy in performing ADL and the perception of the body as a working system. This is a very important finding because it emphasises that ADL do not only depend on real physical abilities but also on one's perception of one's own body. According to Schnittker [17], this finding represents a condition in which mental health, specifically the perception of physical functioning, becomes an indicator of general health. In fact, based on our results, it seems that the level of BADL and IADL in the elderly depends primarily on how they perceive their body and its functioning. Physical activity programs enhance the physical abilities of the elderly [47] [48], but it is not clear if they also improve the perception of physical functioning, changing beliefs and perception of the elderly about their body.

Considering self-rated health and pain perception, our data disputes previous studies about the relationships of these variables with ADL in the elderly. The perception of physical functioning is probably more strongly correlated to ADL because it is less general and more specific than the self-rated health and pain perception. Taking into account together the three constructs in our study, only the perception of physical functioning has emerged as a potential predictor of ADL (see also [49]).

Finally, despite the findings of previous studies [22] [23] (Ormel et al., 2002; Penninx et al., 1999), our study findings did not highlight the moderating role of depression. We identified elderly people with traits of depression without evaluating the presence of depression disorders from a clinical point view. We hypothesised that physical abilities and psychological perceptions would be impaired only in elderly with a severe state of depression. 
Considering the operational results of our research, it seems that a more effective program to improve ADL of elderly should consider both physical abilities, specifically balance and upper limb strength, and the perception of physical functioning. That is, elderly people have to be aware that their physical abilities have improved, and they have to increase confidence in the potential of their own body. If positive changes in physical abilities are accompanied by a positive perception of body functioning, elderly people will be more inclined to maintain their ADL. Our study indicates that BADL and IADL in the elderly are a matter of physical functioning, real and perceived. This should be kept into account when analysing BADL and IADL in the elderly.

Our study had some limitations. The sample size was limited; despite this, we were able to administer a complex and time-expensive battery of psychological and physical tests. To confirm our findings, future studies should include a larger sample size. Furthermore, we administered only a self-reporting questionnaire and the use of objective measures may yield more precise results, especially in the analysis of autonomy in ADL.

Despite these limitations, our study has its merits. Our findings provide fundamental indications about the physical correlates of ADL in the elderly, distinguishing between BADL and IADL, which represent two distinct phenomena in the elderly, especially from a physical point of view; and they should be studied separately. Among a wide range of physical abilities, balance and upper limb strength appeared to play the most important role in the maintenance of BADL and IADL, respectively. Furthermore, we discovered that the perception of the physical functioning of one's own body is a variable that must be taken into account because it has a strong connection with both BADL and IADL.

\section{Conclusion}

Elderly people with sound balance skills and upper limb strength have a high level of autonomy in the performance of BADL and IADL. The perception of physical functioning also has a strong relationship with autonomy in ADL. That is, elderly people who perceive their body as highly functioning are more autonomous. ADL in the elderly seems to depend essentially on physical functioning in the real and perceived dimensions. Real and perceived physical functioning contributes equally to the ADL of elderly people and they should both be considered in the design of effective interventions for the promotion of ADL and in single-case approaches.

\section{Acknowledgements}

Research presented in this article has been supported by Regione Piemonte, Direzione e Innovazione Ricerca e Università, Bando Scienze Umane e Sociali 2008 (ID 59), for their contribution to ACT ON AGEING study. The authors would like to express their thanks to the JSPS Postdoctoral Fellowship Program for Foreigner Researchers FY2012.

\section{References}

[1] Menec, V.H. (2003) The Relation between Everyday Activities and Successful Ageing: A 6-Year Longitudinal Study. Journal of Gerontology Series B. Psychological Sciences and Social Sciences, 58B, 74-82. http://dx.doi.org/10.1093/geronb/58.2.S74

[2] Barucha, A.J., Pandav, R., Shen, C., Dodge, H.H. and Ganguly, M. (2004) Predictors of Nursing Facility Admission: A 12-Year Epidemiological Study in the United States. Journal of the American Geriatric Society, 52, 434-439. http://dx.doi.org/10.1111/j.1532-5415.2004.52118.x

[3] Gaugler, J.E., Duval, S., Anderson, K.A. and Kane, R.L. (2007) Predicting Nursing Home Admission in the U.S.: A Meta-Analysis. Bio Med Cental Geriatrics, 7, 13.

[4] Hjaltadottir, I., Hallberg, I.R., Ekwall, A.K. and Nyberg, P. (2001) Predicting Mortality of Residents at Admission to Nursing Home: A Longitudinal Cohort Study. BMC Health Medic Research, 11, 86. http://dx.doi.org/10.1186/1472-6963-11-86

[5] Millan-Calenti, J.C., Tubio, J., Pita-Fernandez, S., Gonzales-Abraldes, I., Lorenzo, T., Fernandez-Arruty, T. and Maseda, A. (2010) Prevalence of Functional Disability in Activities of Daily Living (ADL), Instrumental Activities of Daily Living (IADL) and Associated Factors, as Predictors of Morbidity and Mortality. Archives of Gerontology and Geriatrics, 50, 306-310. http://dx.doi.org/10.1016/j.archger.2009.04.017

[6] Vermeulen, J., Neyens J.CL., van Rossum, E., Spreeuwenberg, M.D. and De Witte, L.P. (2011) Predicting ADL Disability in Community-Dwelling Elderly People Using Physical Frailty Indicators: A Systematic Review. Bio Med Central Geriatrics, 11, 33. 
[7] Stuck, A.E., Walthert, J.M., Nikolaus T., Bula C.J., Hohmann, C. and Beck, J.C. (1999) Risk Factors for Functional Status Decline in Community-Living Elderly People: A Systematic Literature Review. Social Science \& Medicine, 48, 445-469. http://dx.doi.org/10.1016/S0277-9536(98)00370-0

[8] Huang, W., Perera, S., Van Swearingen, J. and Studenski, S. (2010) Performance Measures Predict Onset of Activity of Daily Living Difficulty in Community-Dwelling Older Adults. Journal of the American Geriatric Society, 58, 844852. http://dx.doi.org/10.1111/j.1532-5415.2010.02820.x

[9] Van Kan, G.A., Rolland Y., Andrieu, S., Bauer, J., Beauchet, O., Bonnefoy, M. and Vellas, B. (2009) Gait Speed at Usual Pace as a Predictor of Adverse Outcomes in Community-Dwelling Older People. An International Academy of Nutrition and Ageing (IANA) Task Force. The Journal of Nutrition, Health and Aging, 13, 881-889. http://dx.doi.org/10.1007/s12603-009-0246-z

[10] Perrig-Chiello, P., Perrig, W., Uebelbacher, A. and Stahelin, H. (2006) Impact of Physical and Psychological Resources on Functional Autonomy in Old Age. Psychology, Health \& Medicine, 11, 470-482. http://dx.doi.org/10.1080/13548500600726633

[11] Onder, G., Penninx, B.W.J.H., Ferrucci, L., Fried, L.P., Guralnik, J.M. and Pahor, M. (2003) Measures of Physical Performance and Risk for Progressive and Catastrophic Disability: Results from the Women’s Health and Aging Study. Journals of Gerontology Series A. Biological Sciences and Medical Sciences, 60, 74-79. http://dx.doi.org/10.1093/gerona/60.1.74

[12] Chou, C., Hwang, C.L. and Wu, Y.T. (2012) Effect of Exercise on Physical Function, Daily Living Activities, and Quality of Life in the Frail Older Adults: A Meta-Analysis. Archives of Physical Medicine and Rehabilitation, 93, 237-244. http://dx.doi.org/10.1016/j.apmr.2011.08.042

[13] Gu, M.O. and Conn, V.S. (2008) Meta-Analysis of the Effects of Exercise Interventions on Functional Status in Older Adults. Research in Nursing \& Health, 31, 594-603. http://dx.doi.org/10.1002/nur.20290

[14] Daniels, R., van Rossum, E., de Witte, L., Kempen, G.I.J.M. and van den Heuvel, W. (2008) Interventions to Prevent Disability in Frail Community-Dwelling Elderly: A Systematic Review. BMC Health Services Research, 8, 278. http://dx.doi.org/10.1186/1472-6963-8-278

[15] Jylha, M. (2009) What Is Self-Rated Health and Why Does It Predict Mortality? Towards a Unified Conceptual Model. Social Science \& Medicine, 69, 307-316. http://dx.doi.org/10.1016/j.socscimed.2009.05.013

[16] Cesare, M., Onder, G., Zamboni, V., Manini, T., Shorr, R.I., Russo, A., Bernabei, R., Pahor, M. and Landi, F. (2008) Physical Function and Self-Rated Health Status as Predictors of Mortality: Results from Longitudinal Analysis in the ilSIRENTE Study. BMC Geriatrics, 8, 34.

[17] Schnittker, J. (2005) When Mental Health Becomes Health: Age and the Shifting Meaning of Self-Evaluations of General Health. Milbank Quarterly, 83, 397-423. http://dx.doi.org/10.1111/j.1468-0009.2005.00407.x

[18] Johnson, R.J. and Wolinsky, F.D. (1993) The Structure of Health Status among Older Adults: Disease, Disability, Functional Limitation, and Perceived Health. Journal of Health and Social Behavior, 34, 105-121. http://dx.doi.org/10.2307/2137238

[19] Hall-Lord, M.L., Larsson, G. and Steen, B. (1999) Chronic Pain and Distress in Older People: A Cluster Analysis. International Journal of Nursing Practice, 5, 78-85. http://dx.doi.org/10.1046/j.1440-172x.1999.00157.x

[20] Covinsky, K.E., Lindquist, K., Dunlop, D.D. and Yelin, E. (2009) Pain, Functional Limitations and Ageing. Journal of the American Geriatrics Society, 57, 1556-1561. http://dx.doi.org/10.1111/j.1532-5415.2009.02388.x

[21] Candela, F., Zucchetti, G. and Magistro, D. (2013) Individual Correlates of Autonomy in Activities of Daily Living of Institutionalized Elderly Individuals: An Exploratory Study in a Holistic Perspective. Holistic Nursing Practice, 27, 284-291. http://dx.doi.org/10.1097/HNP.0b013e31829b9483

[22] Ormel, J., Rijsdijk, F.V., Sullivan, M., van Sonderen, E. and Kempen, G.I.J.M. (2002) Temporal and Reciprocal Relationship between IADL/ADL Disability and Depressive Symptoms in Late Life. Journal of Gerontology Series B. Psychological Sciences and Social Sciences, 57, 338-347. http://dx.doi.org/10.1093/geronb/57.4.P338

[23] Penninx, B.W.J.H., Leveille, S., Ferrucci, L., van Eijk, J.T. and Guralnick, J.M. (1999) Exploring the Effect of Depression on Physical Disability: Longitudinal Evidence from the Established Populations for Epidemiologic Studies of Elderly. American Journal of Public Health, 89, 1346-1352. http://dx.doi.org/10.2105/AJPH.89.9.1346

[24] Schneider, G., Driesch, G., Kruse, A., Wachter, M., Nehen, H. and Heuft, G. (2004) What Influences Self-Perception of Health in the Elderly? The Role of Objective Health Condition, Subjective Well-Being and Sense of Coherence. Archives of Gerontology and Geriatrics, 39, 227-237. http://dx.doi.org/10.1016/j.archger.2004.03.005

[25] Cutler, D.M. (2001) Declining Disabilities among the Elderly. Health Affairs, 20, 11-27. http://dx.doi.org/10.1377/hlthaff.20.6.11

[26] Jones, C.J. and Rikli, R.E. (2002) Measuring Functional Fitness in Older Adults. The Journal of Active Ageing, 25-30.

[27] Katz, S., Ford, A.B., Moskowitz, R.W., Jackson, B.A. and Jaffe, M.W. (1963) Studies of Illness in the Aged: The In- 
dex of ADL: A Standardized Measure of Biological and Psychosocial Function. Journal of the American Medical Association, 185, 914-919. http://dx.doi.org/10.1001/jama.1963.03060120024016

[28] Lawton, M.P. and Brody, E.M. (1969) Assessment of Older People: Self-Maintaining and Instrumental Activities of Daily Living. The Gerontologist, 9, 179-186. http://dx.doi.org/10.1093/geront/9.3_Part_1.179

[29] LaPlante, M.P. (2010) The Classic Measure of Disability in Activities of Daily Living Is Biased by Age But an Expanded IADL/ADL Measure Is Not. The Journals of Gerontology Series B. Psychological Sciences and Social Sciences, 65, 720-732. http://dx.doi.org/10.1093/geronb/gbp129

[30] Sturnieks, D.L., St George, R. and Lord, S.R. (2008) Balance Disorders in the Elderly. Clinical Neurophysiology, 38, 467-478. http://dx.doi.org/10.1016/j.neucli.2008.09.001

[31] Hobeika, C.P. (1999) Equilibrium and Balance in the Elderly. Ear, Nose \& Throat Journal, 78, 558-562.

[32] Folstein, M., Folstein, S. and McHugh, P.R. (1975) Mini-Mental State: A Practical Method for Grading the Cognitive State of Patients for the Clinician. Journal of Psychiatric Research, 12, 189-198. http://dx.doi.org/10.1016/0022-3956(75)90026-6

[33] National Institute of Statistics (2010) Annuario Statistico Italiano 2011 [Statistical Italian Yearbook-2011] [Data File]. ISTAT, Roma. http://www.istat.it

[34] Kempen, G.I., Miedema, I., Ormel, J. and Molenaar, W. (1996) The Assessment of Disability with the Groningen Activity Restriction Scale. Conceptual Framework and Psychometric Properties. Social Science \& Medicine, 43, 16011610. http://dx.doi.org/10.1016/S0277-9536(96)00057-3

[35] Gill, T.M., Robinson, J.T. and Tinetti, M.E. (1998) Difficulty and Dependence: Two Components of the Disability Continuum among Community-Living Older Persons. Annals of Internal Medicine, 128, 96-101. http://dx.doi.org/10.7326/0003-4819-128-2-199801150-00004

[36] Rikli, R.E. and Jones, C.J. (1999) The Development and Validation of a Functional Fitness Test for CommunityResiding Older Adults. Journal of Aging and Physical Activity, 7, 129-161.

[37] Podsiadlo, D. and Richardson, S. (1991) The Timed "Up \& Go": A Test of Basic Functional Mobility for Frail Elderly Persons. Journal of the American Geriatrics Society, 39, 142-148.

[38] Jones, C.J., Rikli, R.E., Max, J. and Noffal, G. (1998) The Reliability and Validity of a Chair Sit-and-Reach Test as a Measure of Hamstring Flexibility in Older Adults. Research Quarterly for Exercise and Sport, 69, 338-343. http://dx.doi.org/10.1080/02701367.1998.10607708

[39] Apolone, G. and Mosconi, P. (1999) The Italian SF-36 Health Survey: Translation, Validation and Norming. Journal of Clinical Epidemiology, 51, 1025-1036. http://dx.doi.org/10.1016/S0895-4356(98)00094-8

[40] Fava, G.A. (1983) Assessing Depressive Symptoms across Cultures: Italian Validation of the CES-D Self-Rating Scale. Journal of Clinical Psychology, 39, 249-251. http://dx.doi.org/10.1002/1097-4679(198303)39:2<249::AID-JCLP2270390218>3.0.CO;2-Y

[41] Hocking, R.R. (1976) The Analysis and Selection of Variables in Linear Regression. Biometrics, 32, 1-50.

[42] Baron, R.M. and Kenny, D.A. (1986) The Moderator-Mediator Variable Distinction in Social Psychological Research: Conceptual, Strategic, and Statistical Considerations. Journal of Personality and Social Psychology, 51, 1173-1182. http://dx.doi.org/10.1037/0022-3514.51.6.1173

[43] Naik, A.D., Concato, J. and Gill, T.M. (2004) Bathing Disability in Community-Living Older Persons: Common, Consequential, and Complex. Journal of the American Geriatrics Society, 52, 1805-1810. http://dx.doi.org/10.1111/j.1532-5415.2004.52513.x

[44] Okumiya, K.K., Matsubayashi, K.K., Nakamura, T.T., Fujisawa, M.M., Osaki, Y.Y., Doi, Y.Y. and Ozawa, T.T. (1999) The Timed "Up \& Go" Test and Manual Button Score Are Useful Predictors of Functional Decline in Basic and Instrumental ADL in Community-Dwelling Older People. The Journal of the American Geriatrics Society, 47, 497-498.

[45] Shumway-Cook, A., Brauer, S. and Woollacott, M. (2000) Predicting the Probability for Falls in Community-Dwelling Older Adults Using the Timed Up \& Go Test. Physical Therapy, 80, 896-903.

[46] Ho, K.H., Matsubayashi, K., Wada, T., Kimura, M., Kita, T. and Saijoh, K. (2002) Factors Associated with ADL Dependence: A Comparative Study of Residential Care Home and Community-Dwelling Elderly in Japan. Geriatrics \& Gerontology International, 2, 80-86. http://dx.doi.org/10.1046/j.1444-1586.2002.00026.x

[47] Magistro, D., Liubicich, M.E., Candela, F. and Ciairano, S. (2014) Effect of Ecological Walking Training in Sedentary Elderly People: Act on Aging Study. The Gerontologist, 54, 611-623. http://dx.doi.org/10.1093/geront/gnt039

[48] Liubicich, M.E., Magistro, D., Candela, F., Rabaglietti, E. and Ciairano, S. (2012) Physical Activity and Mobility Function in Elderly People Living in Residential Care Facilities. “Act on Aging”: A Pilot Study. Advances in Physical Education, 2, 54-60. http://dx.doi.org/10.4236/ape.2012.22010 
[49] Liubicich, M.E., Candela, F., Magistro, D., Rabaglietti, E. and Ortega, E. (2012) Physical Functioning: The Mediating Effect on ADLs and Vitality in Elderly Living in Residential Care Facilities. "Act on Ageing”: A Pilot Study. Health (1949-4998), 4, 407-414.

\section{Note}

ADL: Activity of Daily Living

BADL: Basic Activity of Daily Living

IADL: Instrumental Activity of Daily Living 
Scientific Research Publishing (SCIRP) is one of the largest Open Access journal publishers. It is currently publishing more than 200 open access, online, peer-reviewed journals covering a wide range of academic disciplines. SCIRP serves the worldwide academic communities and contributes to the progress and application of science with its publication.

Other selected journals from SCIRP are listed as below. Submit your manuscript to us via either submit@scirp.org or Online Submission Portal.
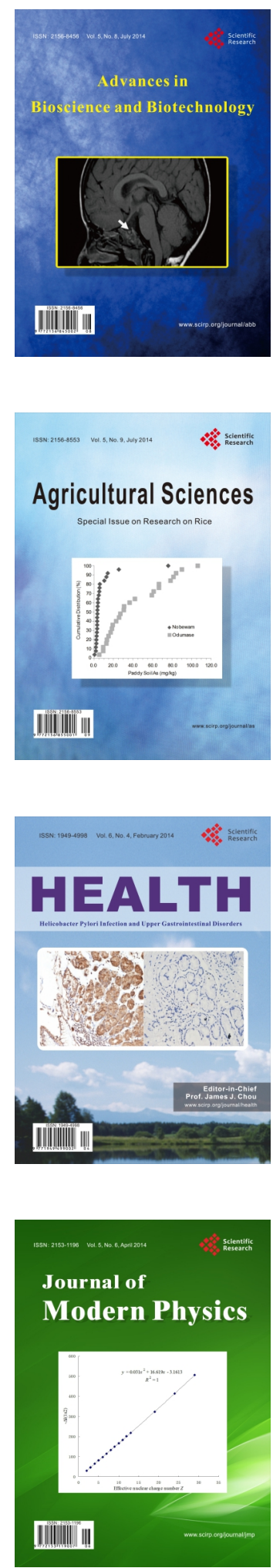
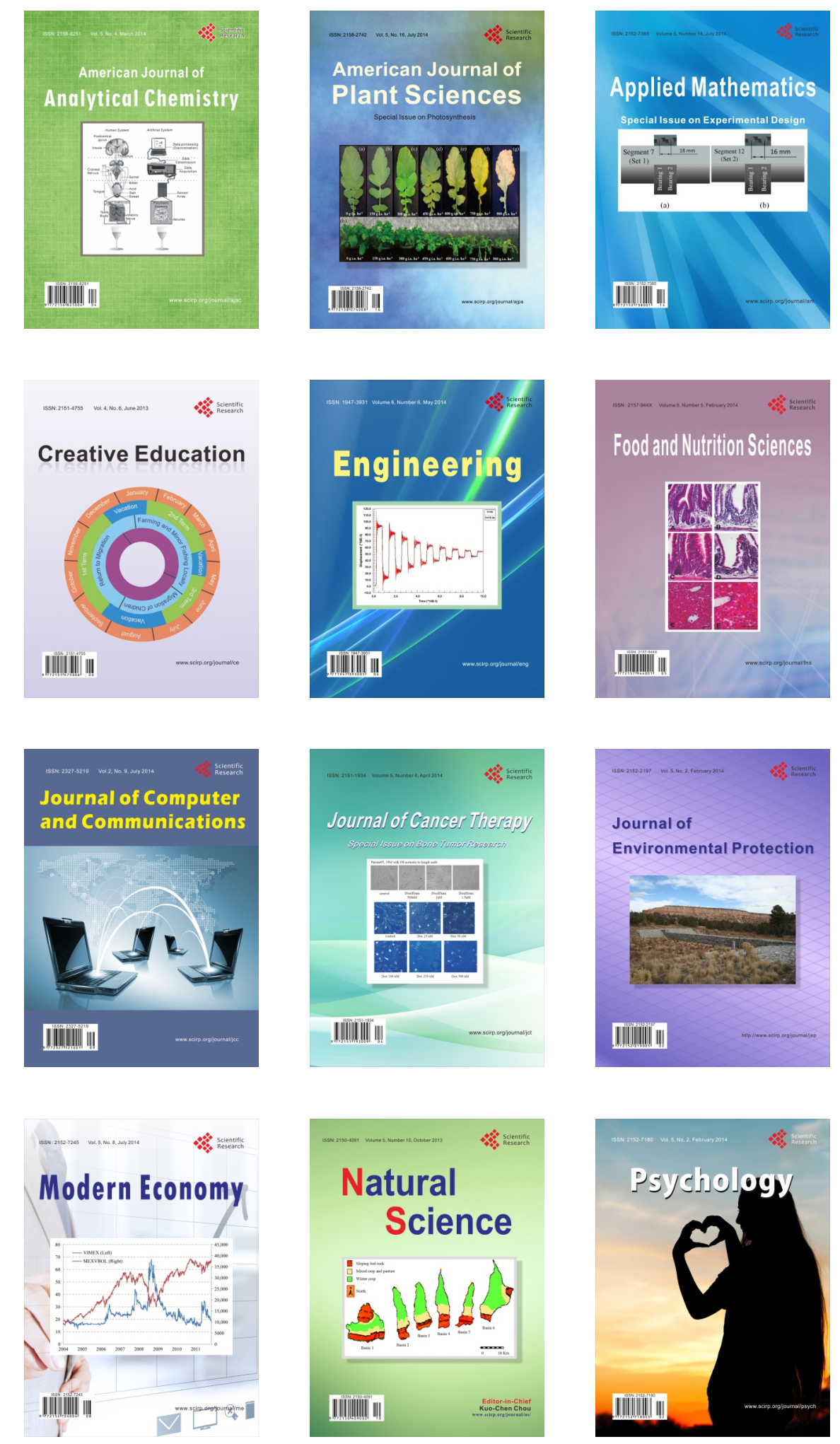